\title{
CATHODIC QUANTUM DOT FACILITATED ELECTROCHEMILUMINESCENT DETECTION IN BLOOD
}

\author{
Alasdair J. Stewart, Kelly Brown, Lynn Dennany* \\ WestCHEM, Department of Pure and Applied Chemistry, University of Strathclyde, Technology and Innovation Centre \\ 99 George Street, Glasgow, G1 1RD, UK \\ *corresponding author's email: lynn.dennany@strath.ac.uk
}

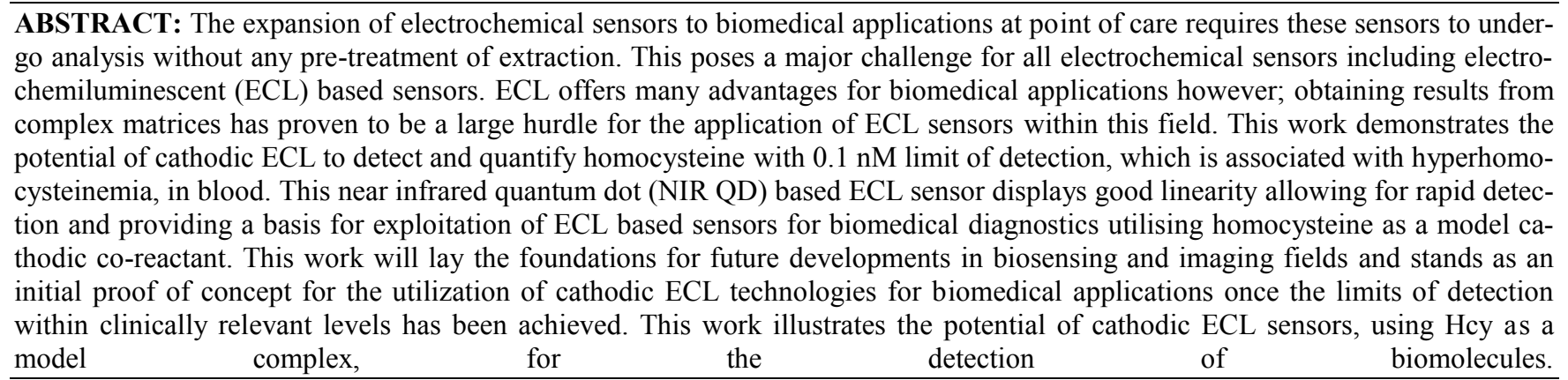

Due to the ability of near infrared quantum dots (NIR QDs) to produce detectable ECL signals within blood thus minimising the issue of tissue auto-fluorescence has expanded the range of potential applications within the arena of biomedical diagnostics. ${ }^{1,2}$ Due to the presence of haemoglobin, the absorption spectrum of whole blood has presented a major hurdle for the exploitation of ECL based sensors. ${ }^{3}$ Typically, blood has an absorbance maxima at 420 and $540 \mathrm{~nm}$ with a minimum at $\sim 805 \mathrm{~nm} .{ }^{4}$ NIR QDs with emissions above $805 \mathrm{~nm}$ therefore will have significantly less quenching within blood samples. This illustrates the promise NIR QDs present for exploitation within ECL biosensors ${ }^{5-7}$ with the potential for direct analysis within complex biological matrices including blood. This study will undertake initial examinations into the cathodic ECL behaviour and performance of NIR QDs in blood. As such, there is a clear requirement for examination of these properties to showcase the applicability of this type of electrochemical systems for use in biological samples.

Homocysteine (Hcy) is an $\alpha$-amino acid that is formed in $v i$ vo through metabolism of methionine. Typical blood Hcy levels are up to $15 \mu \mathrm{M}$, with concentrations above this resulting in hyperhomocysteinemia. ${ }^{8}$ Hyperhomocysteinemia has been linked with pulmonary embolism, stroke, and deep vein thrombosis and ischaemic heart disease..$^{9-12}$ This is because Hcy and its cyclic metabolite homocysteine thiolactone modify the behaviour of endothelial cells, which can promote vascular injury as their surface becomes a pro, rather than anticoagulant. ${ }^{13,14}$ They also promote platelet aggregation ${ }^{15}$ and oxidative stress due to the reactivity of the sulfhydryl group. ${ }^{16}$ Detection of homocysteine tends to be via fluorescence coupled to high-performance liquid chromatography, ${ }^{17,18}$ electrochemical, ${ }^{19}$ or colorimetric methods. ${ }^{20}$ There are currently no methods for the detection of Hcy directly from blood samples or using ECL as the detection method. Hcy contains a sulfhydryl group, which are potent radical quenchers ${ }^{21,22}$ and so it was proposed that detection of Hcy could be accomplished through monitoring a decrease in ECL intensity. Here we report on the proof of concept for the potential application of cathodic ECL detection in blood without the need for pretreatment or extraction, using Hcy as a model cathodic biomarker. We have used Hcy to highlight the new potential avenues for electrochemical sensors.

\section{EXPERIMENTAL}

\section{Materials}

Qdot ${ }^{\circledR} 800$ ITK $^{\mathrm{TM}}$ organic quantum dots, $(1 \mu \mathrm{M}$ in decane) were obtained from Invitrogen. Lumidot ${ }^{\mathrm{TM}} 560$ and $640 \mathrm{~nm}$ QDs, (5 $\mathrm{mg} / \mathrm{mL}$ in toluene), chitosan (medium molecular weight, 75 - $85 \%$ de-acetylated), and all other chemicals were purchased from Sigma-Aldrich. All solutions were prepared in milli-Q water $(18 \mathrm{~m} \Omega \mathrm{cm})$.

Bovine whole blood samples utilised within this study were obtained from Wishaw Abattoir Ltd following University of Strathclyde ethical approval. These were stored in aliquots at $20{ }^{\circ} \mathrm{C}$. Aliquots were defrosted at room temperature on the day of analysis and used immediately.

\section{Instrumentation}

A CH instrument model 760D electrochemical analyser using a standard 3 electrode set-up including a $3 \mathrm{~mm}$ diameter $\mathrm{GC}$ working electrode, $\mathrm{Pt}$ wire counter electrode and $\mathrm{Ag} / \mathrm{AgCl}$ $3 \mathrm{M} \mathrm{KCl}$ reference electrode purchased from IJ Cambria Scientific Ltd (UK) was utilised to record all electrochemical measurements. GC electrodes were cleaned following the pro- 
cedures outlined previously by Stewart et. al. ${ }^{23} \mathrm{~A}$ scan rate of $100 \mathrm{mV} \mathrm{s}^{-1}$ and sample interval of $1 \mathrm{mV}$ across a potential range outlined in each figure was used throughout this work. ECL and electrochemical responses were recorded using a $\mathrm{CH}$ instrument model 760D connected to a Hamamatsu H1072320 PMT which had a wavelength range of 230 to $920 \mathrm{~nm}$. The PMT was biased at $\pm 5 \mathrm{~V}$. All electrochemical experiments were carried out within a light-tight Faraday cage in such as manner as to have the PMT window positioned directly below the GC electrode at room temperature.

\section{Preparation of CdSeTe/ZnS core-shell QD-chitosan composite film}

$\mathrm{CdSeTe} / \mathrm{ZnS}$ QDs were prepared as described previously by Stewart et. al. ${ }^{23-25} 3 \mu \mathrm{L}$ of 1:1 (v/v) solution of QDs and chitosan were drop-cast onto the working electrode surface and dried in the fridge for $1 \mathrm{~h}$ in the dark. As a control, a film containing bare QDs in water was examined. QD concentration in the film was altered by mixing the water-soluble QDs with a suitable volume of water prior to mixing in a $1: 1(\mathrm{v} / \mathrm{v})$ ratio with chitosan. ${ }^{26}$ These QDs were stable over a period of 3 months and the composite films were stable over multiple scans.

\section{Preparation of samples}

Hcy samples ranging from 1 to $60 \mathrm{mM}$ Hcy were prepared in $1 \mathrm{mM} \mathrm{K} 2 \mathrm{~S}_{2} \mathrm{O}_{8}$ in $0.1 \mathrm{M}$ PBS. Blood samples were spiked with Hcy to obtain final concentrations of Hcy in blood ranging from 1 to $6 \mathrm{mM}$. Blood samples containing $1 \mathrm{mM} \mathrm{K}_{2} \mathrm{~S}_{2} \mathrm{O}_{8}$ in $0.1 \mathrm{M}$ PBS were prepared as previously outlined. ${ }^{23}$

\section{RESULTS AND DISCUSSION}

\section{Electrochemical characterization}

The electrochemical behaviour of these QD modified electrodes was interrogated via cyclic voltammetry (CV). Figure 1 (a) shows the cathodic voltammograms from CV of a blank electrode and a QD/chitosan film in blood. Blank GC electrode exhibits a single, small irreversible reduction peak at $0.35 \mathrm{~V}$, consistent with reduction of dissolved $\mathrm{O}_{2}{ }^{27}$ The QD/chitosan film voltammogram also contains this peak, with two further reduction processes at -1.15 and $-1.85 \mathrm{~V}$. The peak at $-1.15 \mathrm{~V}$ has not been seen previously (in buffered aqueous solutions), which suggests that it is related to both the QDs and a species within solution. Whole blood contains a variety of species including proteins, carbohydrates and hormones that are potentially redox active and could interact with the positively charged QDs. ${ }^{28}$ This peak increases as the QD concentration rises, confirming this peak is directly related to a reduction process involving the QDs (See Supplementary Figure $\mathrm{S} 1)$. The occurrence of this reduction peak only in the presence of a $\mathrm{QD} /$ chitosan film in blood suggests the process is dependent upon interaction between a species in solution and the QDs. This may be the reduction of a species in blood that is catalysed by QDs or reduction of a QD bioconjugate that forms following immersion of the QD/chitosan film in blood. The peak at $-1.85 \mathrm{~V}$ is consistent with that in buffered aqueous solutions ${ }^{25,29,30}$ and is therefore related to a secondary reduction process of the QDs. The slight shift in peak potential is related to the poorer electrochemical environment of blood compared to a buffered solution, which will have an impact on the transfer of electrons at the electrode surface and hinder reduction.
This data indicates that the cathodic electrochemical behaviour of these QD composite films in blood is comparable to results obtained in PBS indicating the electrochemistry is not influenced substantially by this complex biological matrix at the potentials being examined in this study.
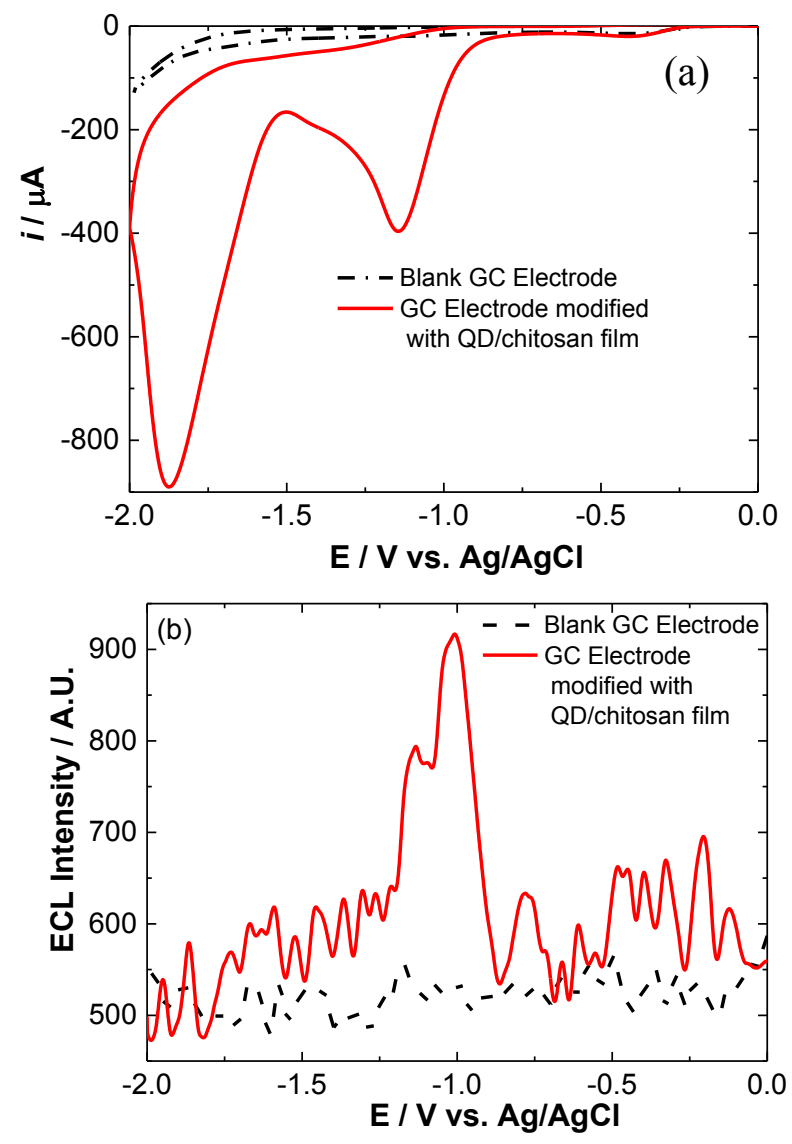

Figure 1: (a) The black dashed line shows the typical CV response of an unmodified GC electrode and the red line represents the electrochemical response of the $800 \mathrm{~nm} \mathrm{QD/chitosan} \mathrm{compo-}$ site film in blood at a scan rate of $100 \mathrm{mV} \mathrm{s}^{-1}$ over the potential range $-2.00 \leq v \leq 0.00 \mathrm{~V}$ vs $\mathrm{Ag} / \mathrm{AgCl}$. (b) ECL signals recorded simultaneously with the traces from (a).

\section{NIR QD cathodic ECL response in blood}

Previous work has shown intense ECL signals can be obtained using NIR QDs in buffered solutions and that oxidative ECL can be attained in blood. ${ }^{23,31}$ The detection of NIR QDs for cathodic ECL has not been achieved or examined directly from whole blood, and so investigation of this process was required to confirm a detectable signal was produced and that this signal was sensitive to changes in the system. The advantage of cathodic ECL is that it opens up the possibility of detecting additional analytes which do not undergo any anodic electrochemistry or ECL, thereby increasing the potential number of applications to which ECL systems can be applied.

The occurrence of a cathodic ECL response from NIR QDs in blood with no additional co-reactants was first investigated. This was to determine whether any alteration in ECL behaviour was occurring through interactions with any species present within a blood sample. The detected response of the QDs in blood is shown in Figure 1 (b). No ECL signal is observed in the absence of QDs indicating that there are no ECL active emitters in the blood sample within the cathodic region exam- 
ined. Immobilisation of the QD/chitosan film on the electrode surface generates a small reduction peak upon potential scanning at $-1.00 \mathrm{~V}$, as shown in Scheme 1. This compares to reduction peaks at -1.00 and $-1.35 \mathrm{~V}$ when the same films are run in PBS, as shown in Figure S1.

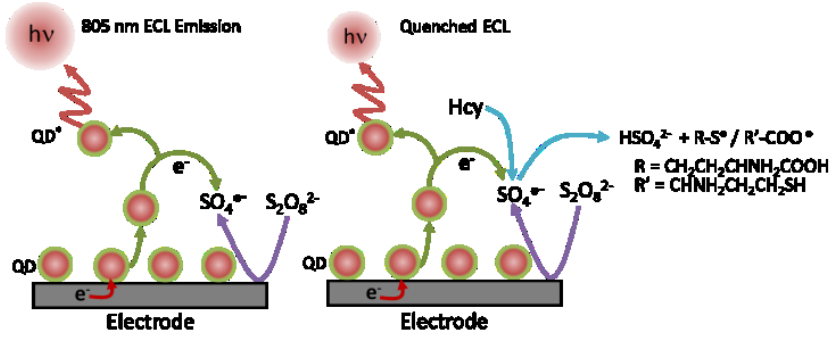

Scheme 1: A schematic representation of the electrochemical processes occurring to produce the ECL and quenched ECL response in the absence and presence of Hcy.

When analysed in PBS solution, reactive oxygen species (ROS) are expected to act as the co-reactant within the system. ROS are created through the oxygen reduction reaction (ORR), which has three common routes. ${ }^{17}$ The favoured pathway is determined predominantly by the electrode material, electrolyte and the catalyst, in this case the QDs. GC electrodes are known to catalyse 2-electron reductions via a complex process that comprises a number of transient intermediate species. ${ }^{17} \mathrm{~A}$ variety of these are likely to be involved in the ECL pathways of the two peaks observed in PBS. ${ }^{17,32,33}$

This was confirmed through the observation of a significant loss in signal intensity following sample de-aeration (See Supplementary Figure S1). Determination of peak specific ROS acting as co-reactant was attempted through the addition of thiourea, a free radical scavenger with particular activity towards hydroxyl radicals, and superoxide dismutase (SOD). ${ }^{34,35}$

The appearance of a peak at $-1.0 \mathrm{~V}$ in both blood and PBS dictates the same ECL processes are occurring and that blood constituents are not affecting the mechanism of ECL production at this potential. As stated, the ECL mechanism of response at this potential involves the interaction between reduced QDs and non-radical products of the ORR. A loss of signal intensity in blood is likely due to reactions of these nonradical species with molecules in blood, such as the consumption of $\mathrm{OH}^{-}$by $\mathrm{H}_{2} \mathrm{CO}_{3}$ to form $\mathrm{HCO}_{3}{ }^{-}$, which is an essential reaction for maintenance of blood $\mathrm{pH}^{36} \mathrm{~A}$ minimal degree of light absorption and scattering by blood will also occur as its absorbance in the NIR region is not zero. ${ }^{4,23}$

The loss of ECL signal at $-1.35 \mathrm{~V}$ in blood indicates that the $\mathrm{OH}^{*}$ is not present at sufficient concentrations to elicit a detectable ECL response. This is most probably caused by quenching of the radical by a species in blood. As $\mathrm{OH}^{\cdot}$ formation is dependent upon $\mathrm{O}_{2}$ followed by $\mathrm{H}_{2} \mathrm{O}_{2}$ reduction, its concentration in solution will already be very low, so any quenching results in this complete loss of response. As expected, the lifetime of radical species, and therefore the concentration available for QD hole injection, appears to decrease in blood due to the presence of free radical scavengers (such as uric acid and glutathione). ${ }^{25,37,38}$

However, the detection of an ECL response directly from blood, even without an additional co-reactant and with radical quenching taking place, was a significant discovery and instils considerable confidence in the capacity of NIR QDs to gener- ate a detectable ECL signal from within a blood sample. Enhancement of this ECL signal was previously shown via the addition of an $\mathrm{K}_{2} \mathrm{~S}_{2} \mathrm{O}_{8}$ co-reactant to the blood sample and was comparable to that observed in the $\mathrm{K}_{2} \mathrm{~S}_{2} \mathrm{O}_{8}-\mathrm{PBS}$ system, as seen in Supplementary Figure S1.

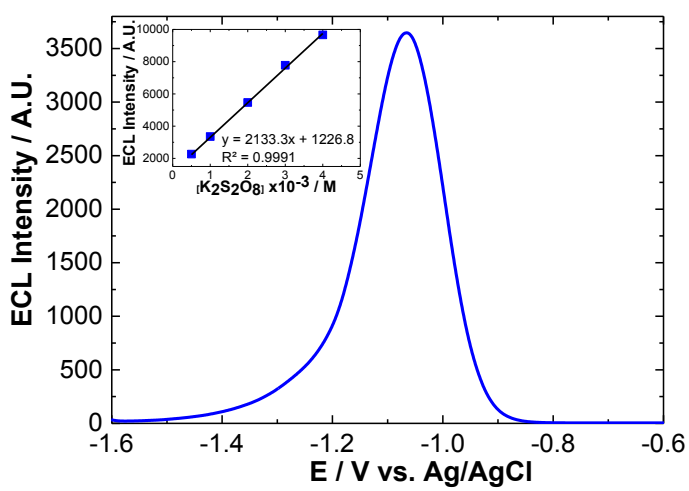

Figure 2: A typical ECL signal observed for a $800 \mathrm{~nm}$ QD/chitosan composite film obtained from a blood sample spiked with $1 \mathrm{mM} \mathrm{K}_{2} \mathrm{~S}_{2} \mathrm{O}_{8}$ at a scan rate of $100 \mathrm{mV} \mathrm{s}^{-1}$ over the potential range $-1.60 \leq v \leq-0.60 \mathrm{~V} v s$. $\mathrm{Ag} / \mathrm{AgCl}$ and the linear relationship of this response with $\left[\mathrm{K}_{2} \mathrm{~S}_{2} \mathrm{O}_{8}\right]$ in blood (inset).

Compared to the PBS response, there is a small shift in peak potential caused by slower electron transfer within blood. Although radical quenching will still occur in blood, there is clearly still a sufficient concentration of $\mathrm{SO}_{4}{ }^{--}$within the ECL active zone to allow for the production of an intense ECL signal with the QDs. The rapid electron transfer kinetics of this system, a consequence of the high standard reduction potential of the $\mathrm{SO}_{4}{ }^{--} / \mathrm{SO}_{4}{ }^{2-}$ couple, ${ }^{25,39}$ will help minimize any interference due to the free radical scavengers within blood. Determination of the responsiveness of this ECL signal to changes in $\mathrm{SO}_{4}{ }^{-}$concentration was examined through spiking of blood samples with an increasing concentration of $\mathrm{K}_{2} \mathrm{~S}_{2} \mathrm{O}_{8}$ (Figure 2). This shows a linear dependence of ECL response with $\mathrm{K}_{2} \mathrm{~S}_{2} \mathrm{O}_{8}$ concentration in blood.

This data shows the enhancement of NIR QD ECL in blood through addition of a suitable co-reactant $\left(\mathrm{K}_{2} \mathrm{~S}_{2} \mathrm{O}_{8}\right)$. This confirms that strong QD ECL emission in the NIR region can be produced directly in blood samples and that it is responsive to a small reactive molecule $\left(\mathrm{SO}_{4}{ }^{-}\right.$in this case). This was a very promising result as it highlighted the ability of NIR QDs to detect a species within blood that was very likely involved in a number of competing reactions with alternative molecules in the system. Detection from blood will always be affected by these competing reactions due to the presence of naturallyoccurring interferents and so the ability of NIR QDs to detect this molecule in blood provided great confidence in their biosensing ability in such conditions.

\section{NIR vs visible region ECL - Light penetration through blood}

A major benefit of NIR QDs over visible region QD ECL materials is their capacity for NIR emission. The results shown in this study have illustrated that a strong ECL signal can be generated and detected directly from blood using these NIR QDs. However, investigations have yet to be carried out to determine whether this response is superior to that generated from visible region QDs. 


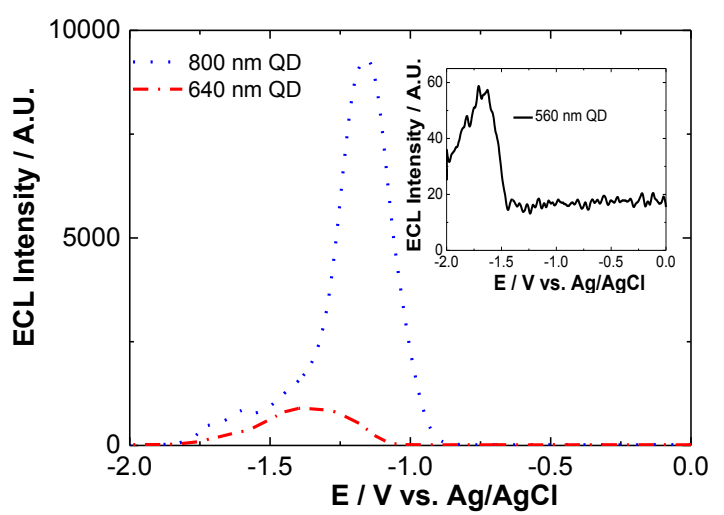

Figure 3: ECL dependence of $800 \mathrm{~nm}$ (blue dotted line), $640 \mathrm{~nm}$ (red dashed line) and $560 \mathrm{~nm}$ (black line in inset) QD/chitosan films over the potential range $-2.00 \leq v \leq 0.00 \mathrm{~V} v s$. $\mathrm{Ag} / \mathrm{AgCl}$ observed in a $1 \mathrm{mM} \mathrm{K}_{2} \mathrm{~S}_{2} \mathrm{O}_{8}$ spiked blood sample in $0.1 \mathrm{M}$ PBS.

The penetration of detectable ECL light intensity through blood from 800, 640 and $560 \mathrm{~nm}$ QDs was examined. In the cathodic region, $\mathrm{K}_{2} \mathrm{~S}_{2} \mathrm{O}_{8}$ was used as the co-reactant as it generated the strongest ECL emission. This showed a similar trend to those obtained for anodic $\mathrm{ECL}^{23}$ as illustrated in Figure 3 and Table 1. The emission maximum for these QDs was $800 \mathrm{~nm}$, however, the ECL emission was slightly shifted to $805 \mathrm{~nm}$ which has previously been observed for surface confined ECL luminophores. ${ }^{21,23,26,40}$

Table 1: Reduction potentials and corresponding ECL intensities of 800, 640, and $560 \mathrm{~nm}$ QDs in blood containing $1 \mathrm{mM}$ $\mathrm{K}_{2} \mathrm{~S}_{2} \mathrm{O}_{8}$.

\begin{tabular}{|l|l|l|}
\hline $\begin{array}{l}\text { QD emission } \boldsymbol{\lambda} / \\
\mathbf{n m}\end{array}$ & $\begin{array}{l}\boldsymbol{E}_{\boldsymbol{p c}} / \text { V. vs } \\
\mathbf{A g} / \mathbf{A g C l}\end{array}$ & $\begin{array}{l}\text { ECL Intensity / } \\
\text { A.U. }\end{array}$ \\
\hline 800 & -1.15 & 9299 \\
\hline 640 & -1.35 & 897 \\
\hline 560 & -1.65 & 58 \\
\hline
\end{tabular}

In the cathodic region, the potential of maximum intensity follows the expected trend of decreasing potential as QD size deceases (and therefore energy of the lowest unoccupied molecular orbital (LUMO) increases). An ECL signal is seen with all QDs, however, the detected response from the $800 \mathrm{~nm}$ QDs is significantly more intense than that for the 640 or $560 \mathrm{~nm}$ QDs (10 and 160 times more intense respectively) for the same QD concentration. The detected response from the 640 $\mathrm{nm}$ QDs is 15 times more intense than that from the $560 \mathrm{~nm}$ QDs. These results indicate that as the wavelength of emitted light increases, the penetrability of this light through blood also increases. This is in line with the optical absorption of whole blood, which decreases with increasing wavelength, reaching a minimum at approximately $800 \mathrm{~nm} .{ }^{4,41}$ This illustrates the capacity of NIR QD based cathodic ECL for direct analysis within complex biological matrices such as blood.

Overall these results have shown that cathodic NIR QD ECL in blood is sensitive to addition of a small, reactive molecule, producing a strong enhancement in ECL intensity. The intense signal obtained with the NIR QD - $\mathrm{K}_{2} \mathrm{~S}_{2} \mathrm{O}_{8}$ system in blood suggests that direct detection of low concentration analytes in blood could be possible using this system. Therefore, this work provides the groundwork for development of cathodic
NIR QD ECL biosensors for direct analysis within complex biological matrices including blood. The ECL responses of this system towards other related species in blood has been inspected. This included uric acid, ascorbic acid, glucose, urea and citric acid. All of these produced an ECL response but only for anodic ECL and therefore did not interfere with the response for this current system.

\section{Response variability}

The inter-sample response variability was investigated in order to determine the effect of different blood samples on the ECL response (See Supplementary Figure S1). The average intra-sample relative standard deviation was $8.3 \%$. An intersample relative standard deviation of $10.0 \%$ was observed, which is within an acceptable range. This shows that the ECL behaviour of the NIR QDs is consistent across different blood samples.

\section{Homocysteine detection}

To illustrate the potential of the ECL systems and in particular these composite NIR QDs films for bioanalysis and detection in blood, we demonstrated the ability of this set-up to detect Hcy within blood samples. The influence of Hcy concentration on the ECL response of NIR QDs composite in PBS was first investigated. An ECL signal at $-1.00 \mathrm{~V}$ is observed, which decreases in intensity as the concentration of Hcy increases as shown in Figure 4, with a limit of detection of 0.232 $\mu \mathrm{M}$. The shift in reduction potential compared to blood (Figure 2) is associated with faster electron transfer between precursor species in PBS, as there are fewer interfering species present within the buffer compared with the blood sample. The capability of NIR QDs for the detection of homocysteine through cathodic ECL has therefore been exhibited within the buffered system. The same methodology could then be applied to blood samples with confidence.

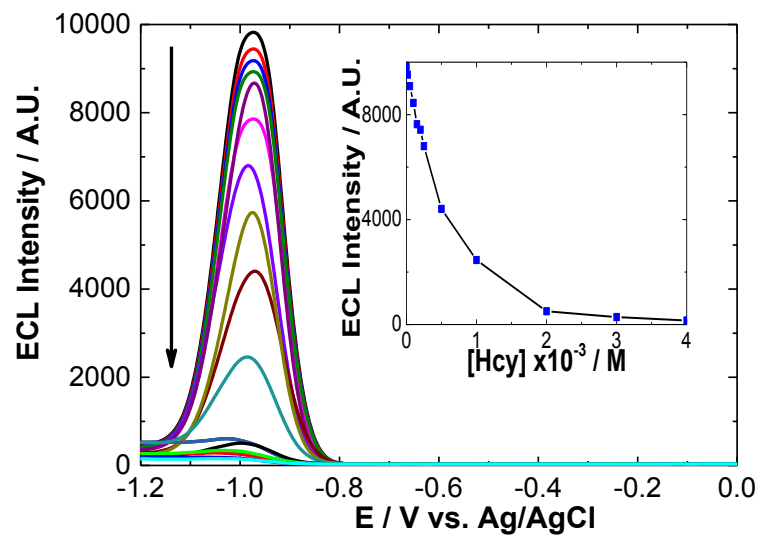

Figure 4: Dependence of ECL signals from the QD composite films on the concentration of $20 \mu \mathrm{M}$ to $4 \mathrm{mM}$ Hcy in $1 \mathrm{mM}$ $\mathrm{K}_{2} \mathrm{~S}_{2} \mathrm{O}_{8}$ in $0.1 \mathrm{M}$ PBS (black represents blank control) at $100 \mathrm{mV}$ $\mathrm{s}^{-1}$ over the potential range $-1.20 \leq v \leq 0.00 \mathrm{~V} v s$. Ag/AgCl. Inset shows the trend of maximum ECL signal at $\sim-1.00 \mathrm{~V}$ vs. $\mathrm{Ag} / \mathrm{AgCl}$ for this data.

\section{ECL response mechanism of homocysteine}

Hcy inhibits the ECL signal through quenching of the radical precursor species, $\mathrm{SO}_{4}^{-}$- following equations 1 and $2 .{ }^{21,22}$

$$
\begin{aligned}
& \mathrm{SO}_{4}{ }^{--}+R-S H \rightarrow R-S^{\bullet}+\mathrm{HSO}_{4}^{-} \\
& 2 R-S^{\bullet} \rightarrow R-S-S-R
\end{aligned}
$$


where $\mathrm{R}$ is $\mathrm{CH}_{2} \mathrm{CH}_{2} \mathrm{CHNH}_{2} \mathrm{COOH}$. The sulfhydryl group of Hcy donates a proton to $\mathrm{SO}_{4}{ }^{--}$forming a radical thiol species (equation (1)), which rapidly dimerises (equation (2)). Alternatively, quenching of $\mathrm{SO}_{4}{ }^{-}$can occur via the carboxylic acid moiety of Hcy (equation (3) and (4)). ${ }^{42}$

$$
\begin{aligned}
& \mathrm{SO}_{4}^{\cdot-}+\mathrm{R}-\mathrm{COOH}+\mathrm{O}_{2} \rightarrow \mathrm{R}-\mathrm{COO}^{\bullet}+\mathrm{HSO}_{4}^{-} \\
& \mathrm{SO}_{4}^{--}+\mathrm{R}-\mathrm{COO}^{-} \rightarrow \mathrm{R}-\mathrm{COO}^{\bullet}+\mathrm{SO}_{4}^{2-}
\end{aligned}
$$

where $\mathrm{R}$ is $\mathrm{CHNH}_{2} \mathrm{CH}_{2} \mathrm{CH}_{2} \mathrm{SH}$. In equation 3 a proton is abstracted from the $\mathrm{C}-\mathrm{H}$ bond forming a carboxyl radical and bisulfate anion. Carboxyl radicals can also be formed through oxidation of the carboxylate anion by $\mathrm{SO}_{4}{ }^{-}$(equation (4)). It is likely that each of these processes contribute to the quenching of $\mathrm{SO}_{4}{ }^{-}$and therefore reduction in the observed ECL signal, however, it is not clear which is the dominant process.

As with our previous study, the relationship between ECL emission intensity and quencher was expressed by the SternVolmer equation (5). ${ }^{40,43,44}$

$$
\frac{I_{0}}{I}=1+K_{S V}[Q]
$$

The initial ECL intensity and the ECL intensity at a known concentration of the quencher [Q] are represented by $\mathrm{I}_{0}$ and $\mathrm{I}$, while the Stern-Volmer quenching constant is represented by $\mathrm{K}_{\mathrm{SV}}$. The data obtained here did not exhibit a linear dependence as predicted by the Stern-Volmer equation, as is evident from the data in Figure 4 (See Supplementary Figure S2). As the quenching process can be affected by surface confinement within a polymer film, ${ }^{26,45-47}$ the Hindered Access Model was utilised to account for this within this system. This considers the confinement of the QDs and $\mathrm{SO}_{4}{ }^{--}$within the chitosan film, taking into consideration the differences in accessibility for different species to the quencher molecules within the film. The Hindered Access Model predicts $\left(\mathrm{I}_{0} / \mathrm{I}_{0}-\mathrm{I}\right)$ and $(1 /[\mathrm{Q}])$ have a linear correlation, which results in an intercept equal to $\mathrm{f}_{\mathrm{a}}^{-1}$ and a slope of $\mathrm{f}_{\mathrm{a}} \mathrm{K}_{\mathrm{a}}{ }^{-1}$ (equation (6)), ${ }^{44}$

$$
\frac{I_{0}}{I_{0}-I}=\frac{1}{f_{a}}+\frac{1}{f_{a} K_{a}[Q]}
$$

Where $f_{a}$ is the fraction of accessible species and $K_{a}$ is the Stern-Volmer quenching constant of this accessible fraction. This modified model has previously ${ }^{23}$ been shown to predict an influence of the chitosan polymer on the quenching behaviour as observed in the system (See Supplementary Figure S2). A linear dependence between $20 \mu \mathrm{M}$ and $4 \mathrm{mM}$ is observed, with a corresponding $\mathrm{K}_{\mathrm{a}}$ value of $1.3 \times 10^{3} \mathrm{M}^{-1} \mathrm{~s}^{-1}$. This, in effect, represents the linear range of the sensor and has been used as the standard curve for Hcy detection with a limit of detection of $0.1 \mathrm{nM}$. This is considerably higher than sensitivities observed for alternative ECL based systems. ${ }^{6,48,49}$ However, it should be noted that these limits of detection were achieved in idealised sample matrices and not in complex biological matrices.

The influence of chitosan on the quenching behaviour was confirmed as a film of bare QDs followed a typical SternVolmer relationship (Figure S2), yielding a linear dependence of $\mathrm{I}_{0} / \mathrm{I}$ on $[\mathrm{Q}]$.

\section{Analytical Performance}

Commonly exiting species likely to interfere with the selectivity of this system were examined. These included ascorbic acid, citric acid and uric acid. These are commonly encountered species within blood samples, and as such were used to evaluate the clinical viability and cross-reactivity of this sys- tem with the responses shown in Figure 6. None of these had any significant impact on the observed cathodic ECL response indicating good sensor specificity. It is important to note that these species did produce an anodic ECL response but this did not interfere with the cathodic ECL response monitored for Hcy detection.
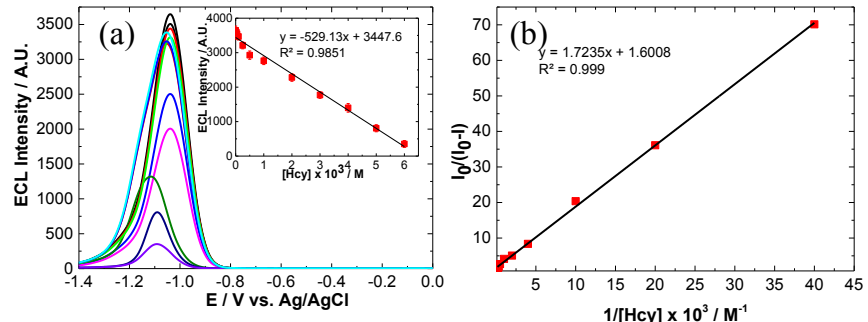

Figure 5: (a) ECL signal of $800 \mathrm{~nm}$ QD/chitosan film in 1 $\mathrm{mM} \mathrm{K}_{2} \mathrm{~S}_{2} \mathrm{O}_{8}$ in blood (black) following additions of 0.025 to 6 $\mathrm{mM}$ Hcy recorded at $100 \mathrm{mV} \mathrm{s}^{-1}$ over the potential range -1.40 $\leq v \leq 0.00 \mathrm{~V} v s$. $\mathrm{Ag} / \mathrm{AgCl}$. Inset shows the maximum ECL signal of $800 \mathrm{~nm}$ composite QD/chitosan film in these solutions at $\sim-1.15 \mathrm{~V}$ vs. $\mathrm{Ag} / \mathrm{AgCl}$. (b) Hindered Access Model plot of $800 \mathrm{~nm} \mathrm{QD} /$ chitosan film in $1 \mathrm{mM} \mathrm{K}_{2} \mathrm{~S}_{2} \mathrm{O}_{8}$ in blood with increasing [Hcy]. The ECL profiles of all these results are shown in supplementary material (Figure S3).

However, cysteine, cystine and methionine do interfere with the detection of Hcy to different extents. All of these molecules are structurally similar to Hcy and undergo similar electrochemical processes. However, their responses were still significantly less than that of Hcy. To realise selectivity, improvements in the current strategy need to be developed to realise real world applications at the desired concentrations. This might include incorporating other materials or using a microfluidic system to remove interferents prior to analysis in the time scale required for detection.

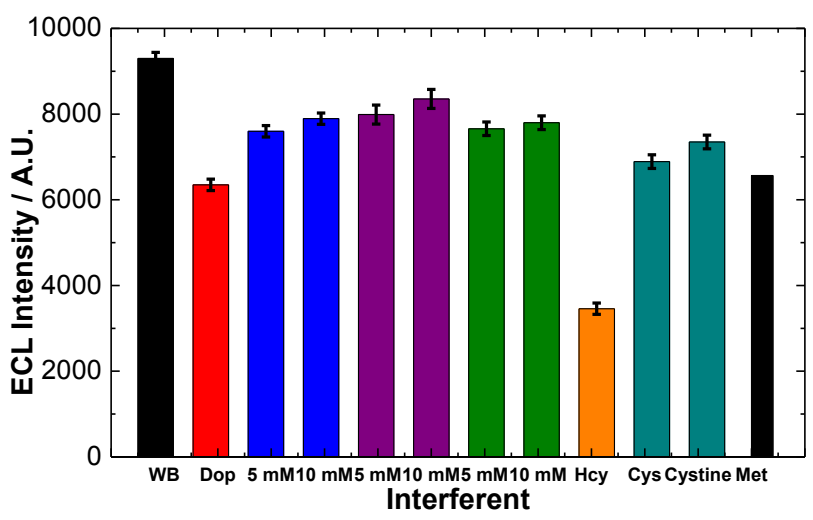

Figure 6. Cathodic ECL signal dependence observed at -1.15 $\mathrm{V}$ for the $800 \mathrm{~nm} \mathrm{QD} /$ chitosan composite film in whole blood (WB) with $1 \mathrm{mM} \mathrm{K} \mathrm{S}_{2} \mathrm{O}_{8}$ with $0.25 \mathrm{mM}$ Hcy (orange), (37.5 $\mu \mathrm{M}$ dopamine (Dop, red)), ascorbic acid (blue), citric acid (purple) at $5 \mathrm{mM}$ and $10 \mathrm{mM}$ respectively as well as cysteine (Cys), cystine and methionine (Met, black) at $10 \mathrm{mM}$. Error bars represent triplicate data points.

As Hcy had the ability to quench NIR QD ECL in buffer, the same investigation was carried out in blood samples. The ECL response in blood spiked with increasing Hcy concentrations is shown in Figure 5 (a), with minor deviations due to extremely low levels of Hcy in the blood samples expected. The results correlated well with high-performance liquid chromatography (HPLC) data obtained for these samples. Indeed, the percent- 
age recoveries for these samples was found to be $\leq \pm 5 \%$ compared to chromatographic analysis undertaken on the same samples as illustrated in Table 2. Some of the discrepancies in the responses maybe due to the presence of interferents such as cysteine, cystine or methionine. Supplementary Figure S4 shows a typical response from the chromatographic analysis obtained.

The profile contains an ECL peak at approximately $-1.15 \mathrm{~V}$, which decreases in intensity as Hcy concentration increases. Movement of this reduction peak suggests that interference between precursor species and constituents in whole blood are affecting electron transfer at the electrode surface. The modified Stern-Volmer plot (Figure 5 (b)) yields a linear relationship between 0.05 and $6 \mathrm{mM}$ Hcy, with a $\mathrm{K}_{\mathrm{a}}$ value of $1.4 \times 10^{2}$ $\mathrm{M}^{-1} \mathrm{~s}^{-1}$.

This quenching rate is $\sim 12$ times slower than that achieved with Hcy in PBS (See Supplementary Figure S2), indicating that constituents in blood are influencing the quenching process and explaining the linear relationship between ECL intensity and [Hcy] observed in blood but not PBS (Figures 4 and $5(a))$. This is likely due to the formation of electrostatic interactions between the amine and/or carboxylic acid moieties of Hcy with charged regions of biomolecules (such as albumin) in blood. This will reduce Hcy quenching efficiency as diffusion of this bulkier complex through chitosan will be hindered and therefore its rate of reaction with $\mathrm{SO}_{4}{ }^{-}$at the electrode surface will decrease. The $\mathrm{K}_{\mathrm{a}}$ in both buffer and blood does not currently allow detection down to clinically relevant levels, however, it is hoped that improvements in biosensor performance would permit this. However, comparison with a chromatographic technique showed comparable results indicating that there is potential for this technology to be utilised once the issues of sensitivity have been addressed.

Table 2. Comparison of HPLC results for Hcy concentration determination to those obtained with this ECL based system for unknown blood serum samples and the corresponding $\%$ recoveries.

\begin{tabular}{|c|l|l|l|}
\hline $\begin{array}{l}\text { “Unknown" } \\
\text { Conc. / mM }\end{array}$ & $\begin{array}{l}\text { Averaged } \\
\text { Cal. Conc. / } \\
\text { mM }\end{array}$ & $\begin{array}{l}\text { HPLC Av- } \\
\text { eraged } \\
\text { Calc. Conc. } \\
\text { / mM }\end{array}$ & $\begin{array}{l}\text { \% Recover- } \\
\text { ies }\end{array}$ \\
\hline 1.00 & 1.03 & 1.06 & 97.2 \\
\hline 3.00 & 2.98 & 3.03 & 98.4 \\
\hline 6.00 & 6.02 & 6.10 & 98.7 \\
\hline
\end{tabular}

\section{CONCLUSION}

This work has shown the applicability of co-reactant NIR QD ECL for the detection of a clinically relevant analyte within blood. Hcy was used as a model complex to highlight the potential of ECL sensors to be applied to this type of analysis as a proof of concept for ECL technology. Although this system did not achieve the high sensitivities or the required selectivity obtained in other electrochemical systems or indeed to current analytical methods for Hcy detection, it does illustrate the capacity of ECL based sensors to detect analytes in blood without the need for complex sample extraction, thereby reducing the amount of sample preparation required and highlighting the expansion of ECL applications into the detection of analytes which undergo cathodic electrochemistry in blood.
Significantly, this is the first example of a cathodic ECL biosensor capable of detecting a target analyte directly in blood. This illustrates the capacity for exploitation of ECL based sensors within biomedical applications. It illustrates the potential of ECL biosensors to effectively detect a medically relevant biomarker directly in complex biological matrices without any sample pre-treatment. Future work will be undertaken to enhance the sensitivities and selectivities and to allow for multiplexed detection and analysis.

\section{ASSOCIATED CONTENT}

\section{Supporting Information}

Supporting material includes ECL responses for the interactions with reactive oxygen species (Figure S1), ECL responses for 1 $\mathrm{mM} \mathrm{K}_{2} \mathrm{~S}_{2} \mathrm{O}_{8}$ in blood with the Stern-Volmer and modified SternVolmer plots for this data (Figure S2). The ECL dependence for the interferents given in Figure 6 (Figure S3). Chromatographic experimental details are also included (Figure S4). This material is available free of charge via the Internet at http://pubs.acs.org.

\section{AUTHOR INFORMATION}

\section{Corresponding Author \\ *1ynn.dennany@strath.ac.uk}

\section{Author Contributions}

The manuscript was written through contributions of all authors.

\section{ACKNOWLEDGMENT}

The authors would like to acknowledge funding from the EU FP7 funding through the Marie Curie Reintegration Grant scheme (PIRG-2010-268236), which has supported this work. LD and KB would also like to acknowledge The Carnegie Trust for $\mathrm{PhD}$ scholarship funding.

\section{REFERENCES}

(1) Xie, W.; An, X.; Chen, L.; Li, J.; Leng, J.; Lü, W.; Zhang, L.; Luo, Y. Tunable phase and upconverting luminescence of Gd3+ codoped NaErF4:Yb3+ nanostructures. Mater. Res. Bull. 2017, 95, 509514.

(2) Chatterjee, D. K.; Rufaihah, A. J.; Zhang, Y. Upconversion fluorescence imaging of cells and small animals using lanthanide doped nanocrystals. Biomaterials 2008, 29, 937-943.

(3) Wray, S.; Cope, M.; Delpy, D. T.; Wyatt, J. S.; Reynolds, E. O. R. Characterization of the near infrared absorption spectra of cytochrome aa 3 and haemoglobin for the non-invasive monitoring of cerebral oxygenation. Biochim. Biophys. Acta, Bioenerg. 1988, 933, 184-192.

(4) Roggan, A.; Friebel, M.; Doerschel, K.; Hahn, A.; Mueller, G. J.; SPIE, 1999, p 11.

(5) Liu, X.; Jiang, H.; Fang, Y.; Zhao, W.; Wang, N.; Zang, G. Quantum Dots Based Potential-Resolution Dual-Targets Electrochemiluminescent Immunosensor for Subtype of Tumor Marker and Its Serological Evaluation. Anal. Chem. 2015, 87, 91639169.

(6) Li, S.-K.; Chen, A.-Y.; Niu, X.-X.; Liu, Z.-T.; Du, M.; Chai, Y.-Q.; Yuan, R.; Zhuo, Y. In situ generation of electrochemiluminescent DNA nanoflowers as a signal tag for mucin 1 detection based on a strategy of target and mimic target synchronous cycling amplification. Chem. Commun. 2017, 53, 96249627.

(7) Yang, H.; Zhang, Y.; Li, L.; Zhang, L.; Lan, F.; Yu, J. Sudokulike Lab-on-Paper Cyto-Device with Dual Enhancement of Electrochemiluminescence Intermediates Strategy. Anal. Chem. 2017, $89,7511-7519$ 
(8) Skibińska, E.; Sawicki, R.; Lewczuk, A.; Prokop, J.; Musiał, W.; Kowalska, I.; Mroczko, B. Homocysteine and progression of coronary artery disease. Kardiol Pol 2004, 60, 197-205.

(9) Boushey, C. J.; Beresford, S. A.; Omenn, G. S.; Motulsky, A. G. A quantitative assessment of plasma homocysteine as a risk factor for vascular disease: Probable benefits of increasing folic acid intakes. JAMA 1995, 274, 1049-1057.

(10) Clarke, R.; Collins, R.; Lewington, S.; Donald, A.; Alfthan, G.; Tuomilehto, J.; Arnesen, E.; Bonaa, K.; Blacher, J.; Boers, G. H. J.; Bostom, A.; Bots, M. L.; Grobbee, D. E.; Brattström, L.; Breteler, M. M. B.; Hofman, A.; Chambers, J. C.; Kooner, J. S.; Coull, B. M.; Evans, R. W.; Kuller, L. H.; Evers, S.; Folsom, A. R.; Freyburger, G.; Parrot, F.; Genest, J., Jr.; Dalery, K.; Graham, I. M.; Daly, L.; Hoogeveen, E. K.; Kostense, P. J.; Stehouwer, C. D. A.; Hopkins, P. N.; Jacques, P.; Selhub, J.; Luft, F. C.; Jungers, P.; Lindgren, A.; Lolin, Y. I.; Loehrer, F.; Fowler, B.; Mansoor, M. A.; Malinow, M. R.; Ducimetiere, P.; Nygard, O.; Refsum, H.; Vollset, S. E.; Ueland, P. M.; Omenn, G. S.; Beresford, S. A. A.; Roseman, J. M.; Parving, H. H.; Gall, M. A.; Perry, I. J.; Ebrahim, S. B.; Shaper, A. G.; Robinson, K.; Jacobsen, D. W.; Schwartz, S. M.; Siscovick, D. S.; Stampfer, M. J.; Hennekens, C. H.; Feskens, E. J. M.; Kromhout, D.; Ubbink, J.; Elwood, P.; Pickering, J.; Verhoef, P.; Von Eckardstein, A.; Schulte, H.; Assmann, G.; Wald, N.; Law, M. R.; Whincup, P. H.; Wilcken, D. E. L.; Sherliker, P.; Linksted, P.; Smith, G. D. Homocysteine and risk of ischemic heart disease and stroke: A metaanalysis. JAMA 2002, 288, 2015-2022.

(11) Danesh, J.; Lewington, S. Plasma Homocysteine and Coronary Heart Disease: Systematic Review of Published Epidemiological Studies. J Cardiovasc Risk 1998, 5, 229-232.

(12) Wald, D. S.; Law, M.; Morris, J. K. Homocysteine and cardiovascular disease: evidence on causality from a meta-analysis. $B M J$ 2002, 325, 1202.

(13) Karolczak, K.; Olas, B. Mechanism of action of homocysteine and its thiolactone in hemostasis system. Physiol. Res. 2009, 58, 623.

(14) Perła-Kaján, J.; Twardowski, T.; Jakubowski, H. Mechanisms of homocysteine toxicity in humans. Amino Acids 2007, 32, 561-572.

(15) Rajkumar, V.; Ragatzki, P.; Sima, A.; Levy, J. Enhanced platelet aggregation, high homocysteine level, and microvascular disease in diabetic muscle infaractions. Endocr. J 1999, 11, 57-60.

(16) Stamler, J. S.; Osborne, J. A.; Jaraki, O.; Rabbani, L. E.; Mullins, M.; Singel, D.; Loscalzo, J. Adverse vascular effects of homocysteine are modulated by endothelium-derived relaxing factor and related oxides of nitrogen. J. Clin. Invest. 1993, 91, 308-318.

(17) Song, H.; Zhang, J.; Wang, X.; Zhou, Y.; Xu, C.; Pang, X.; Peng, X. A novel "turn-on" fluorescent probe with a large stokes shift for homocysteine and cysteine: Performance in living cells and zebrafish. Sens. Actuators, B 2018, 259, 233-240.

(18) Zhang, Y.; Yao, W.; Liang, D.; Sun, M.; Wang, S.; Huang, D. Selective detection and quantification of tryptophan and cysteine with pyrenedione as a turn-on fluorescent probe. Sens. Actuators, B 2018 259, 768-774.

(19) Xu, Q.; Yuan, H.; Dong, X.; Zhang, Y.; Asif, M.; Dong, Z.; He, W.; Ren, J.; Sun, Y.; Xiao, F. Dual nanoenzyme modified microelectrode based on carbon fiber coated with AuPd alloy nanoparticles decorated graphene quantum dots assembly for electrochemical detection in clinic cancer samples. Biosens Bioelectron 2018, 107, 153-162.

(20) Xia, Y.; Zhang, H.; Zhu, X.; Zhang, G.; Yang, X.; Li, F.; Zhang, X.; Fang, M.; Yu, J.; Zhou, H. A highly selective two-photon fluorescent chemosensor for tracking homocysteine via situ reaction. Dyes Pigm. 2018, 155, 159-163.

(21) Dennany, L.; Gerlach, M.; O'Carroll, S.; Keyes, T. E.; Forster, R. J.; Bertoncello, P. Electrochemiluminescence (ECL) sensing properties of water soluble core-shell CdSe/ZnS quantum dots/Nafion composite films. J. Mater. Chem. 2011, 21, 13984-13990.

(22) O'Reilly, E. J.; Conroy, P. J.; Hearty, S.; Keyes, T. E.; O'Kennedy, R.; Forster, R. J.; Dennany, L. Electrochemiluminescence platform for the detection of C-reactive proteins: application of recombinant antibody technology to cardiac biomarker detection. $R S C$ Adv. 2015, 5, 67874-67877.
(23) Stewart, A. J.; Hendry, J.; Dennany, L. Whole Blood Electrochemiluminescent Detection of Dopamine. Anal. Chem. 2015, 87, 11847-11853.

(24) Woelfle, C.; Claus, R. O. Transparent and flexible quantum dot-polymer composites using an ionic liquid as compatible polymerization medium. Nanotechnology 2007, 18, 025402.

(25) Russell, R.; Stewart, A. J.; Dennany, L. Optimising electrogenerated chemiluminescence of quantum dots via co-reactant selection. Anal. Bioanal. Chem. 2016, 408, 7129-7136.

(26) Stewart, A. J.; O’Reilly, E. J.; Moriarty, R. D.; Bertoncello, P.; Keyes, T. E.; Forster, R. J.; Dennany, L. A Cholesterol Biosensor Based on the NIR Electrogenerated-Chemiluminescence (ECL) of Water-Soluble CdSeTe/ZnS Quantum Dots. Electrochim. Acta 2015, $157,8-14$

(27) Bao, L.; Sun, L.; Zhang, Z.-L.; Jiang, P.; Wise, F. W.; Abruña, H. D.; Pang, D.-W. Energy-Level-Related Response of Cathodic Electrogenerated-Chemiluminescence of Self-Assembled CdSe/ZnS Quantum Dot Films. J. Phys. Chem. C 2011, 115, 18822-18828.

(28) Lebedev, A. V.; Pelouch, V.; Ivanova, M. V.; Levitsky, D. O. AQuantitative Evaluation OfRedox-Active Compounds In Human Blood Lipids. Hemoglobin 2011, 35, 247-254.

(29) Haram, S. K.; Quinn, B. M.; Bard, A. J. Electrochemistry of CdS Nanoparticles: A Correlation between Optical and Electrochemical Band Gaps. J. Am. Chem. Soc 2001, 123, 8860-8861.

(30) Chen, S.; Truax, L. A.; Sommers, J. M. AlkanethiolateProtected PbS Nanoclusters: Synthesis, Spectroscopic and Electrochemical Studies. Chem. Mater. 2000, 12, 3864-3870.

(31) Bertoncello, P.; Stewart, A. J.; Dennany, L. Analytical applications of nanomaterials in electrogenerated chemiluminescence. Anal. Bioanal. Chem. 2014, 406, 5573-5587.

(32) Wang, Z.; Song, H.; Zhao, H.; Lv, Y. Graphene-amplified electrogenerated chemiluminescence of CdTe quantum dots for $\mathrm{H} 2 \mathrm{O} 2$ sensing. Luminescence 2013, 28, 259-264.

(33) Devadoss, A.; Dennany, L.; Dickinson, C.; Keyes, T. E.; Forster, R. J. Highly sensitive detection of NADH using electrochemiluminescent nanocomposites. Electrochem. Commun. 2012, 19, 43-45.

(34) Wasil, M.; Halliwell, B.; Grootveld, M.; Moorhouse, C. P.; Hutchison, D. C. S.; Baum, H. The specificity of thiourea, dimethylthiourea and dimethyl sulphoxide as scavengers of hydroxyl radicals. Their protection of $<\mathrm{em}>\alpha</ \mathrm{em}><\mathrm{sub}>1</$ sub $>$ antiproteinase against inactivation by hypochlorous acid. Biochem. $J$. 1987, 243, 867-870.

(35) Prasad, A. K.; Mishra, P. C. Scavenging of superoxide radical anion and hydroxyl radical by urea, thiourea, selenourea and their derivatives without any catalyst: A theoretical study. Chem. Phys. Lett. 2017, 684, 197-204.

(36) Di Mascio, P.; Murphy, M. E.; Sies, H. Antioxidant defense systems: the role of carotenoids, tocopherols, and thiols. Am. J. Clin. Nutr. 1991, 53, 194S-200S.

(37) Ames, B. N.; Cathcart, R.; Schwiers, E.; Hochstein, P. Uric acid provides an antioxidant defense in humans against oxidant- and radical-caused aging and cancer: a hypothesis. Proc. Natl. Acad. Sci. U.S.A. 1981, 78, 6858-6862.

(38) Pippenger, C. E.; Browne, R. W.; Armstrong, D. In Free Radical and Antioxidant Protocols, Armstrong, D., Ed.; Humana Press: Totowa, NJ, 1998, pp 299-313.

(39) Pettinger, B.; Schöppel, H. R.; Gerischer, H. Electroluminescence at semiconductor electrodes caused by hole injection from electrolytes. Ber. Bunsenges. Phys. Chem. 1976, 80, 849-855.

(40) Dennany, L.; Keyes, T. E.; Forster, R. J. Surface confinement and its effects on the luminescence quenching of a rutheniumcontaining metallopolymer. Analyst 2008, 133, 753-759.

(41) O'Reilly, E. J.; Keyes, T. E.; Forster, R. J.; Dennany, L. Deactivation of the ruthenium excited state by enhanced homogeneous charge transport: Implications for electrochemiluminescent thin film sensors. Electrochem. Commun. 2018, 86, 90-93.

(42) Grgić, I.; Podkrajšek, B.; Barzaghi, P.; Herrmann, H Scavenging of SO4- radical anions by mono- and dicarboxylic acids 
in the Mn(II)-catalyzed S(IV) oxidation in aqueous solution. Atmos. Environ. 2007, 41, 9187-9194.

(43) O'Reilly, E. J.; Dennany, L.; Griffith, D.; Moser, F.; Keyes, T. E.; Forster, R. J. Ground and excited state communication within a ruthenium containing benzimidazole metallopolymer. Phys. Chem. Chem. Phys. 2011, 13, 7095-7101.

(44) Lakowicz, J. R. Principles of Fluorescence Spectroscopy; Springer US: Boston, MA, 2006, p 1-26.

(45) Clements, J. H.; Webber, S. E. Fluorescence Quenching Kinetics of Anthracene Covalently Bound to Poly(Methacrylic Acid): Midchain Labeling. J. Phys. Chem. A 1999, 103, 2513-2523.

(46) Deng, S.; Zhang, T.; Zhang, Y.; Shan, D.; Zhang, X. Chronopotentiometric synthesis of quantum dots with efficient surface-derived near-infrared electrochemiluminescence for ultrasensitive microchip-based ion-selective sensing. $R S C A d v$. 2014, 4, 29239-29248.

(47) Eckert, A. R.; Hsiao, J.-S.; Webber, S. E. Photophysics of Adsorbed and Solution Phase End-tagged Poly(ethylene oxide). $J$. Phys. Chem. 1994, 98, 12025-12031.

(48) Xue, J.; Zhang, Z.; Zheng, F.; Xu, Q.; Xu, J.; Zou, G.; Li, L.; Zhu, J.-J. Efficient Solid-State Electrochemiluminescence from HighQuality Perovskite Quantum Dot Films. Anal. Chem. 2017, 89, 82128216.

(49) Zhang, Y.; Li, L.; Zhang, L.; Ge, S.; Yan, M.; Yu, J. In-situ synthesized polypyrrole-cellulose conductive networks for potentialtunable foldable power paper. Nano Energy 2017, 31, 174-182. 


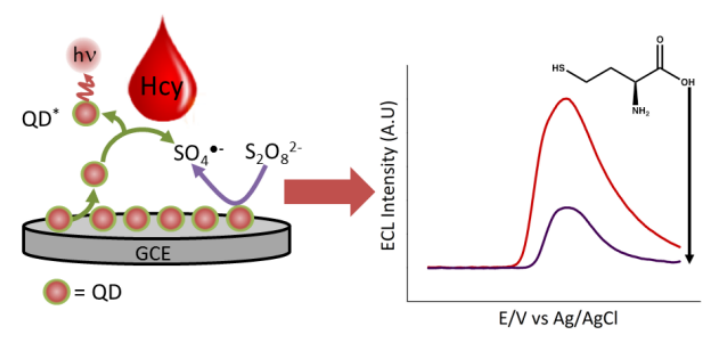

